\title{
Renal vasculitis in Colombia
}

\author{
Ramírez $\mathrm{F}^{1}$, Rojas $\mathrm{W}^{1}$, Jaramillo $\mathrm{D}^{1}$, Ochoa $\mathrm{CD}^{1}$, Toro $\mathrm{CA}^{1}$, Méndez-Patarroyo $\mathrm{P}^{1}$, \\ Coral $\mathrm{P}^{1}$, Cantillo $\mathrm{J}^{3}$, Ramírez $\mathrm{G}^{4}$, Quintana $\mathrm{G}^{1}$, Restrepo $\mathrm{JF}^{1}$, Rondón $\mathrm{F}^{1}$, \\ Aroca $\mathrm{G}^{4}$, Iglesias-Gamarra $\mathrm{A}^{1}$ \\ ${ }^{1}$ Unidad de Reumatología, Universidad Nacional, Bogotá, Colombia \\ 2 Hospital Universitario ,Clínica San Rafael, Bogotá, Colombia \\ 3 Universidad Industrial de Santander, Bucaramanga ,Colombia \\ ${ }^{4}$ Universidad Simón Bolívar, Barranquilla, Colombia
}

\begin{abstract}
Resumen
A retrospective review of publications about primary vasculitis cases was performed from the Colombian medical literature, the clinical and pathological features are described.

The Renal vasculitis occurred in $33.9 \%$ of cases of primary vasculitis reviewed and was more frequent in women. The main clinical, hematological, immunological variables and nephropathology and immunosuppressive treatments used findings are described.
\end{abstract}

Palabras clave: Renal vasculitis

\section{Vasculitis renal in Colombia}

\section{Summary}

Se realizó una revisión retrospectiva de publicaciones en la literatura médica Colombiana de los casos con Vasculitis Primarias, se describen las características clínicas y patológicas.

La vasculitis Renal se presentó en el $33.9 \%$ de los casos de vasculitis primaria revisados y fue más frecuente en mujeres. Se describen las principales variables clínicas, hematológicas, inmunológicas y los hallazgos de nefropatología, así como los tratamientos inmunosupresores utilizados.

Key words: Vasculitis renal

\section{Introduction}

$\mathrm{P}$ rimary vasculitides are a heterogeneous group of systemic diseases characterized by inflammatory cell infiltration in blood vessel walls causing destruction and fibrinoid necrosis ${ }^{1}$. These can involve one or more vessels of various calibers, hence that the clinical manifestations depend largely on which of these arteries are compromised.
According to the etiology, they may be primary, if a cause is not identified, or secondary to an infectious process, induced by medication or an autoimmune disease ${ }^{2}$.

With respect to the caliber of the blood vessels, these can be large (aorta and its main branches), medium (smaller vessels that are the main branches of the aorta, but still having an intima, elastic lamina, tunica media, and adventitia), and small (all those 
below macroscopic size such as capillaries, post-capillary venules, venules, andarterioles) in size. Among the large vessel vasculitides are Takayasu's arteritis and giant cell arteritis. Those that affect the medium caliber include polyarteritis nodosa (PAN), Kawasaki disease, and vasculitides of the small vessel or associated with

ANCAs are Wegener's granulomatosis, Churg Strauss syndrome, and microscopic polyangiitis (MPA). Several attempts to classify the different types of systemic vasculitis have been made. The first attempt was made by Zeek in 1952 and was based according to the size of the blood vessel ${ }^{3}$. Subsequently, the American College of Rheumatology established in

1990 the classification criteria for different forms of vasculitis, in an attempt to unify concepts and create a uniform scheme to allow inclusion of patients in clinical studies ${ }^{4}$. With the development of knowledge on vasculitis and the association between antineutrophil cytoplasmic antibodies (ANCA) in the development of small vessel vasculitis, the Chapel Hill Consensus in $1994^{5}$ proposed a system of nomenclature and definition for the most common non-infectious forms of vasculitis. In 2012, this consensus was updated and it was decided to dispense with medical eponyms and rename the different vasculitis according to their histopathological presentation, hence Wegener's granulomatosis was renamed granulomatosis with polyangiitis and Churg Strauss syndrome was termed eosinophilic granulomatosis with polyangiitis ${ }^{6}$. These classification systems, nomenclature, and definitions are not diagnostic criteria for the different types of vasculitis, allowing the unification of concepts and facilitating the inclusion of patients in clinical trials.

The lack of uniformity in concepts, as well as their low incidence, has made their study difficult. However it is considered that giant cell arteritis is the most common form of systemic vasculitis, being more frequent in patients over 50 years of age. Studies in populations of Scandinavians and Americans of Nordic descent (Olmsted County, Minnesota, USA) showed an annual incidence of 15-35/100,000 and $18.8 / 100,000$ in people over 50 years of age ${ }^{7,8}$. In Japan, there was a reported a prevalence of 1.47 /
100,000 in people over 50 years of age ${ }^{9}$. Studies suggest that this is predominantly a disease of Caucasians but these studies have been of mainly Scandinavian countries and the existence of ethnic studies is not known.

Kawasaki disease has been best studied in Japan, where they have documented an incidence of $100 / 100,000$ of children younger than 5 years old ${ }^{10}$, and in another Asian country like China, there have been incidences as high as 18-27.8 / 100,000 in Beijing and as low as 2.4/ 100,000 in Shanxi in children younger than 5 years old ${ }^{11,12}$. Studies in the United States and in England have found annual incidences of 8-18/100.000 and 4-8/100.000 respectively. Estimates have been made to determine the prevalence of PAN. In France, it is considered to be 30/1,000,000 and in Sweden 1.6/1,000,000 ${ }^{13}$, while the incidence in Australia is $1.1 / 1,000,000$ per year ${ }^{14}$.

Epidemiological studies of this entity have been difficult given the changes in the definition of pathology. Additionally it has been observed that a large number of these cases have been associated with the presence of HBV infection, especially in Asia.

As for small vessel vasculitis, granulomatosis with polyangiitis has an annual incidence that varies by region from $0.5-8$ cases $/ 1,000,000$, being higher in some European countries such as Sweden and Finland ${ }^{15,16}$. In Latin America, particularly in Peru, there is a reported incidence of 0.5 cases per million ${ }^{17}$.

The microscopic polangiitis is an entity that is generally lower in frequency than granulomatosis with polyangiitis. In the UK, the incidences reported vary from 3.3-8.9/1,000,000 ${ }^{18,19}$, which when compared with the data in other countries shows a higher prevalence and incidence in these populations.

Eosinophilic granulomatosis with polyangiitis has an overall incidence of 1-3 cases / million. It is the least common of the ANCA-associated vasculitis, is more common in women, with a peak onset of 6575 years of age. With the exception of a report by Sanchez et al in Peru, the epidemiology of primary vasculitis in Latin America is scarce.

In Bogota, Colombia there was the opportunity to recover a historical cohort of San Juan de Dios Hospital of 165.556 biopsies, of which 104 corresponded 
to primary vasculitis and of these 79 corresponded to small vessel vasculitis with a frequency of 47.2 / 100,000 biopsies $^{20}$. This demonstrates the need for population studies to identify the frequency of vasculitis in the Colombian population.

Epidemiologic studies of impaired renal function in AAV are scare and reports come from Norwich (England), Lugo (Spain), Sweden, and Miyazaki prefecture in Japan.

The aim of the present study was to retrospectively analyze all the renal vasculitis cases collected by our group, in order to identify the most important features of this entity in Colombia.

\section{Methods}

This is a descriptive and retrospective study. The aim of the study was to identify all the patients attending the Rheumatology Department of the Universidad Nacional de Colombia (Bogotá, Colombia) as outpatients or hospitalized with a diagnosis of primary

systemic vasculitis from 2000 until 2010. Also, we invited other Rheumatology units in Colombia to send us new cases of vasculitis that they have identified. The medical records from every case recognized were reviewed retrospectively to confirm the vasculitis classification using the Chapel Hill Consensus Conference definitions.

Inclusion criteria for the present study were: 1) $\mathrm{Pa}$ tients with a diagnosis of primary systemic vasculitis with or without histological confirmation; 2) Renal involvement suspected by hematuria, proteinuria, or both with or without renal insufficiency, and/or pathological changes in renal biopsies supporting renal vasculitis. From every case of renal vasculitis the gender, age, type of vasculitis, laboratory findings (including ANCAs), treatment, features from renal biopsies, and outcomes were recorded. Thedata from the study were presented as mean, frequencies, and percentages. This study was approved by the Research Ethics Committee at the Universidad Nacional de Colombia.

\section{Results}

We identified and collected 175 patients with primary vasculitis. Most of patients were women (63.7\%). The most frequent vasculitides were TA $(21.8 \%)$, PAN (18.9\%), WG (14.9\%) and MPA (14.9\%), with overall average ages of $28.3(+14.6), 48.2(+20.5)$, $45(+10.9)$ and $42.9(+14.4)$ respectively (Table 1$)$. Those patients with vasculitis associated to ANCAs (AAV) such as MPA and WG had positive p-ANCA (73.9\%) andpositive c-ANCA (84.9\%) respectively.

There were 59 cases with renal involvement (33.9\%), mainly MPA (38.9\%) and GW (32\%), and to a lesser extent PAN (11.8\%) and HSP (10\%). Of the vasculitides associated to ANCAs (AAV), $69.5 \%$ of MPA with renal impairment were $\mathrm{p}$-ANCA positive and $68.4 \%$ of GW were c-ANCA positive. To note, 10 cases from PAN were p- ANCA positive but only 6 had renal involvement. Also, 7 patients with Henoch Schölein Purpura had renal involvement but none were ANCA positive (Table 2).

Primary vasculitis with renal involvement was found mainly in women ( $59 \%$ vs $41 \%$ ), however, the WG cases occurred mostly in men (68\% vs $32 \%$ ) (Table 2 ). The age of diagnosis, as expected, was over 40 years old, with an exception of patients with HSP, which is a disease of younger people.

Laboratory findings from these patients show a tendency to have low levels of hemoglobin and high levels of leucocytes, platelets, and globular sediment rate as well. In MPA, low renal function was very important (Table 3).

Renal involvement of vasculitis was treated with glucocorticoids in $100 \%$ of cases, and often required cyclophosphamide ( $>80 \%)$. Renal biopsies were obtained from 37 patients $(62 \%)$ with vasculitis and renal involvement, mostly from MPA (54\%) (Table 3).

\section{Discussion}

Primary vasculitis is a group of disorders characterized by destructive wall vessel inflammation. Many 
Table 1

\begin{tabular}{|c|c|c|c|c|c|c|}
\hline \multicolumn{7}{|c|}{ Table 1} \\
\hline \multicolumn{7}{|c|}{ Frequency of primary vasculitis in Colombia, serologic features and renal involvement. } \\
\hline Primary vasculitis & $\mathbf{N}$ & Gender $\mathbf{M} / \mathbf{F}$ & Age & PANCA + & C ANCA + & Renal involvement \\
\hline \multicolumn{7}{|l|}{ Large vessel } \\
\hline Takayasu's arteritis & 38 & $2 / 24$ & $28.30(+14.6)$ & 1 & 0 & 2 \\
\hline Giant cell arteritis & 6 & $2 / 4$ & $64.6(+11.63)$ & 0 & 1 & 0 \\
\hline \multicolumn{7}{|l|}{ Medium vessel } \\
\hline Kawasaki arteritis & 5 & $2 / 3$ & $2.76(+2.52)$ & 0 & 0 & 1 \\
\hline Panarteritis nodosa & 33 & $11 / 22$ & $48.27(+20.51)$ & 10 & 1 & 6 \\
\hline \multicolumn{7}{|l|}{ Small vessel } \\
\hline Wegener's granulomatosis & 26 & $15 / 11$ & $45(+10.9)$ & 2 & 17 & 19 \\
\hline Microscopic polyangiitis & 26 & $10 / 16$ & $42.95(+14.4)$ & 17 & 7 & 23 \\
\hline Churg-Strauss syndrome & 7 & $3 / 2 *$ & $43.16(+13.28)$ & 1 & 0 & 0 \\
\hline Henoch-Schonlein purpura & 12 & $2 / 10$ & $17.45(+6.69)$ & 0 & 0 & 7 \\
\hline Cryoglobulinemia & 1 & $0 / 1$ & N/A & 0 & 0 & 1 \\
\hline Urticarial vasculitis & 4 & $1 / 3$ & $36.5(+20.14)$ & 0 & 0 & 0 \\
\hline Nervous system vasculitis & 7 & $5 / 2$ & $27(+8.51)$ & 0 & 0 & 0 \\
\hline Nodular vasculitis & 3 & $1 / 2$ & $27(+9.29)$ & 0 & 0 & 0 \\
\hline Buerger's & 2 & $1 / 1$ & $19(+1.41)$ & 0 & 0 & 0 \\
\hline Leukocytoclastic vasculitis & 4 & $2 / 2$ & 29 & 0 & 0 & 0 \\
\hline Total & 174 & & & 31 & 26 & 59 \\
\hline *: Missing data & & & & & & \\
\hline
\end{tabular}

\section{Table 2}

Serologic features of Colombian patients with primary vasculitis and renal involvement.

\begin{tabular}{|lllllll|}
\hline Primary vasculitis & $\begin{array}{l}\text { Renal } \\
\text { involvement } \\
\text { Male }\end{array}$ & Female & Age & $\begin{array}{l}\text { C ANCA+ } \\
\text { and Renal } \\
\text { involvement }\end{array}$ & $\begin{array}{l}\text { PANCA+ } \\
\text { and Renal } \\
\text { involvement }\end{array}$ & $\begin{array}{l}\text { Renal } \\
\text { biopsy }\end{array}$ \\
\hline Wegener's granulomatosis & 13 & 6 & $41.16(+10.46)$ & 13 & 1 & 7 \\
Microscopic polyangiitis & 9 & 14 & $42.13(+15.66)$ & 6 & 16 & 20 \\
Henoch-Scholein purpura & 0 & 7 & $21(+5.19)$ & 0 & 0 & 7 \\
Cryoglobulinemia & 0 & 1 & N/A & 0 & 0 & 0 \\
Takayasu's arteritis & 0 & 2 & $38(+21.12)$ & 0 & 2 & 0 \\
Panarteritis nodosa & 1 & 5 & $57(+11.14)$ & 1 & 0 & 0 \\
Kawasaki disease & 0 & 1 & 2 & 0 & 19 & 37 \\
\hline Total & 23 & 36 & & 20 & & 0 \\
\hline
\end{tabular}


Table 3

Laboratory features and treatment of Colombian patients with primary vasculitis and renal involvement.

\begin{tabular}{|c|c|c|c|c|c|c|c|c|c|}
\hline \multirow[t]{2}{*}{$\begin{array}{l}\text { Primary } \\
\text { vasculitis }\end{array}$} & \multicolumn{4}{|l|}{ Laboratories } & \multicolumn{5}{|l|}{ Treatment } \\
\hline & $\begin{array}{l}\text { Hemoglobin } \\
\text { gr/dl }\end{array}$ & $\begin{array}{l}\text { Leukocytes x } \\
103 \times \mathrm{mm} 3\end{array}$ & $\begin{array}{l}\text { Platelets x } \\
\text { mm3 }\end{array}$ & $\mathrm{ESR} \mathrm{mm} / \mathrm{hr}$ & $\begin{array}{l}\text { Creatinine } \\
\mathrm{mg} / \mathrm{dl}\end{array}$ & Steroids & AZA & $\mathrm{CyC}$ & Dialysis \\
\hline $\begin{array}{l}\text { Wegener's } \\
\text { granulomatosis }\end{array}$ & $10.5(+2.2)$ & $9747(+3681)$ & $\begin{array}{l}410533 \\
(+170737)\end{array}$ & $59.7(+23.3)$ & $\begin{array}{l}1.52 \\
(+0.16)\end{array}$ & 19 & 7 & 17 & 2 \\
\hline $\begin{array}{l}\text { Microscopic } \\
\text { poliangiitis }\end{array}$ & $10.9(+2.7)$ & $\begin{array}{l}13570 \\
(+10269)\end{array}$ & $\begin{array}{l}310578 \\
(+167449)\end{array}$ & $33.64(+22.7)$ & $8.95(+5.5)$ & 23 & 13 & 20 & 1 \\
\hline $\begin{array}{l}\text { Henoch-Scholein } \\
\text { purpura }\end{array}$ & $13(+3.56)$ & $\begin{array}{l}10728 \\
(+4704)\end{array}$ & $\begin{array}{l}301000 \\
(+58024)\end{array}$ & $25(+7.5)$ & $\mathrm{N} / \mathrm{A}$ & 5 & 1 & 3 & 0 \\
\hline Cryoglobulinemia & 12,1 & 3700 & 165000 & 13 & $\mathrm{~N} / \mathrm{A}$ & 1 & 0 & 1 & 0 \\
\hline $\begin{array}{l}\text { Takayasu's } \\
\text { arteritis }\end{array}$ & $11.5(+1.13)$ & $8600(+4666)$ & 307000 & $49.5(+13.43)$ & N/A & 2 & 1 & 0 & 0 \\
\hline $\begin{array}{l}\text { Panarteritis } \\
\text { nodosa }\end{array}$ & $10.9(+1.5)$ & $\begin{array}{l}16360 \\
(+5210)\end{array}$ & $\begin{array}{l}527600 \\
(+299367)\end{array}$ & $53.66(+34.11)$ & N/A & 6 & 5 & 4 & 0 \\
\hline \multicolumn{10}{|l|}{ Kawasaki disease } \\
\hline
\end{tabular}

attempts have been made in order to define and classify those pathologies, such as the ACR proposal (1990) and Chapel Hill Concensus (1994), primarily by the size of vessel affected in each entity. There is very little informationabout the epidemiology of primary vasculitis because of its low prevalence worldwide.

Primary vasculitis can affect the kidney with different degrees of severity, whether bycompromising the renal arteries (vasculitis of large and medium vessels) or at thevcapillary level renal glomerulus as in small vessel vasculitis associated with ANCAvneutrophil antibodies. The latter will predominantly present renal involvement withv varying degrees of severity and frequency.

ANCA-associated vasculitides (AAV) are multisystem diseases, which affect small and medium sized vessels and are characterized by the presence of anti-neutrophil cytoplasmic antibodies (ANCAs). These antibodies are directed against neutrophil granule proteins and macrophage proteins. According to the pattern of staining in indirect immunofluorescence, there are cytoplasmic or c-ANCA (mainly directed against proteinase-3, PR3) and perinuclear or p-ANCA (mainly directed againstmyeloperoxidase, MPO). These antibodies are associated with the development of renal involvement and are factors of the aggressiveness and, likewise, the prognosis in the course of the disease. Although both patterns are found in $\mathrm{AAV}$, the c-ANCA pattern is more common in granulomatosis with poliangiits in about $70-80 \%$ of patients, the p-ANCA in PAM in $60 \%$ of patients, and eosinophilic granulomatosis with polyangiitis in about $40 \%$ of patients ${ }^{21}$.

The typical presentation of AAV is a rapidly progressive glomerulonephritis with renal function loss of over $50 \%$ in a few days or weeks, acute renal failure, hematuria, red cell casts, and non-nephrotic range proteinuria, with slight changes in blood pressure ${ }^{22}$.

The importance lies in that about $60 \%$ of patients who at diagnosis may require renalreplacement therapy $^{23}$ and the presence of RPGN is associated with a poor shorttermfunctional prognosis, chronic renal disease, requirement for renal replacement therapy, 
and death if not treated early with immunosuppressive therapy ${ }^{24}$.

The polyangiitis with granulomatosis and microscopic polyangiitis are the AAV which most often affect the kidney. There are different reports which document up to $70 \%$ of renal involvement in granulomatosis with polyangiitis, while in microscopic polyangiitis nearly $100 \%$ of patients develop renal involvement. This is not a very common finding in eosinophilic granulomatous polyangiitis where kidney involvement can be seen in up to $25 \%$. Histologically this renal involvement is characterized by necrosis of capillary loops, crescent-shaped extracapillary proliferation, periglomerular and interstitial infiltration, necrotizing arteritis with the absence of autoimmune deposits ${ }^{25}$ with immunofluorescence. However electron microscopy has shown an increase in thefrequency of immunoglobulin deposits, a finding that is related to the extent of proteinuria ${ }^{26}$.

Although these histopathologic findings have been well characterized, the etiology of ANCA associated vasculitis has not yet been fully determined. Several environmental factors have been associated with the development of ANCAs. Silica exposure has been demonstrated in animal models to induce and increase the speed of apoptosis of neutrophils and monocytes, and this increased apoptosis has been linked to the production of $\mathrm{ANCAs}^{27}$. Bacterial infections, mainly by $\mathrm{S}$. aureus, can induce AAV.

Several mechanisms have been proposed including induction of production of antiproteinase 3, through molecular mimicry mechanisms ${ }^{28}$. Additionally, certain medications such as antithyroid agents, carbimazole, methimazole and propylthiouracil,have been associated with AAV. The latter is related to the development of MPOANCA, with reported incidences ranging from 0.53 to 0.79 per 100,000 patients with severe disease ${ }^{29}$. However, such ANCAs have lower pathogenicity and clinicalmanifestations are less severe and tend to disappear when the drug is stopped $^{30}$.

The main goal of the Rheumatology Department of the Universidad Nacional de Colombia was to recover every case of primary vasculitis published in medical literature and record each case identified by our group and by external Rheumatology groups in Colombia, attending outpatients or hospitalized cases. A previous study published by our group reviewed all the biopsies from the Pathology Department database of the San Juan de Dios Hospital (Bogotá, Colombia). A total of 857 cases of primary vasculitis were identified, mostly TA (13.3\%), Buerger's $(11.2 \%)$ and cutaneous vasculitis and PAN (10\% both). Another study published by our group searched Latin American literature from Pubmed, BIREME, LILACS, and other databases, and found 1605 cases of vasculitis. We showed that Mexico and Brazil had mainly Takayasu's arteritis, and Chile and Peru had MPA. The article also mentions how several diagnoses, such as MPA, have been increasing in the last decades. It may be because the vasculitis classification criteria and definitions have evolved over time as knowledge increases.

There is also scarce information about renal involvement secondary to primary vasculitis. There are a few studies from Norwich (England), Lugo (Spain), Sweden, and Mizayaki (Japan). The majority of patients with renal vasculitis are classified as MPA in the Mizayaki prefecture, where they had a renal vasculitis incidence of $14.8 /$ million. Norwich's study reported an incidence of 5/million, 5.8/million and 1.4/million of MPA, WG and CSS vasculitis respectively. In Sweden, the incidence of WG was $9.8 / \mathrm{mi}$ llion and MPA 10.1/million, with renal involvement in $48 \%$ and $98 \%$ of cases respectively. Similarly, our study now confirms that small vessel vasculitis is the most important cause of renal vasculitis. Of all the patients collected with vasculitis and renal involvement (59/174), $38.9 \%$ and $32 \%$ of patients had MPA and $\mathrm{WG}$, respectively. This result was predictable, because the kidney is made by small vessels.

The average peak age at presentation for AAV is between 65 to 74 years old in the European and Japanese cohorts. However our study revealed a peak incidence in the fourth decade of life for Colombian patients. World literature has not found any differences among gender and AAV, but interestingly, this study suggests that Colombian males are prone to develop MPA with renal involvement.

Results from ANCA analysis showed 65.3\% (17/26) of patients with WG were positive for c-ANCA and 
$65.3 \%(17 / 26)$ of patients with MPA were positive for p-ANCA, which is close to international standards. Renal involvement was seen in $73 \%(19 / 26)$ of patients with WG and $88.4 \%(23 / 26)$ of patients with MPA, respectively. Also 68.4\% (13/19) of patients with WG positive for c-ANCA had renal involvement, and $69.5 \%(16 / 23)$ were positive of p-ANCA. Renal function was impaired in both entities, especially MPA, but only 3.3\% required dialysis. Additionally, 10 patients $(16.9 \%)$ had diagnosis of PAN and were positive for $\mathrm{p}$-ANCA, and two of them had renal involvement. Our group believes that those patients may actually have had MPA but during 1990s the definitions of both pathologies were not clear and they could be misclassified. In fact, fewer cases of PAN and more of MAP diagnosis have been made last years in Colombia.

Other laboratory findings in patients with primary vasculitis and renal involvement showed anemia, leukocytosis, thrombocytosis and an elevated ESR, all of which characterize an inflammatory state.

Due to the lack of epidemiologic information about renal vasculitis, especially in Latinoamerican countries, our group considers that it is very important to identify new cases and collect information from patients as much as it is possible, in order to gain more knowledge about these entities. The present study is the first data (with demographic and serologic features) collected from Colombian patients with renal

vasculitis. However, the number of cases collected and the retrospective nature of this study reduces the power of the results. Also, many cases came from other Rheumatology units and it was difficult to extract this information. On the other hand, renal vasculitis is a rare condition and has a heterogeneous epidemiology (with prevalences and incidences varying among countries, ethnic disparities, etc) which makes this study very important.

These data need to be confirmed in prospective rather than retrospective studies, collecting cases not only from the Rheumatology Department of the Universidad Nacional de Colombia, but also from other units of Rheumatology and Nephrology in Colombia.

\section{Conclusion}

This is the first epidemiologic study to evaluate renal vasculitis in Colombia. The most common causes of renal vasculitis are WG and MPA. The presence of c-ANCA and p-ANCA are associated to both diseases respectively, as international literature describes. Prospective studies are required to confirm data.

\section{Bibliography}

1. Sinico RA, Di Toma L, Radice A. Renal involvement in anti-neutrophil cytoplasmic autoantibody associated vasculitis. Autoimmun Rev. 2013;12(4):477-82.

2. John R, Herzenberg AM. Vasculitis affecting the kidney. Semin Diagn Pathol. 2009;26(2):89-102.

3. ZEEK PM. Periarteritis nodosa; a critical review. Am J Clin Pathol. 1952;22(8):777-90.

4. Bloch DA, Michel BA, Hunder GG, McShane DJ, Arend WP, Calabrese LH, et al. The American College of Rheumatology 1990 criteria for the classification of vasculitis. Patients and methods. Arthritis Rheum. 1990;33(8):1068-73.

5. Jennette JC, Falk RJ, Andrassy K, Bacon PA, Churg J, Gross WL, et al. Nomenclature of systemic vasculitides. Proposal of an international consensus conference. Arthritis Rheum. 1994;37(2):187-92.

6. Jennette JC, Falk RJ, Bacon PA, Basu N, Cid MC, Ferrario F, et al. 2012 revised International Chapel Hill Consensus Conference Nomenclature of Vasculitides. Arthritis Rheum. 2013;65(1):1-11.

7. Nordborg C, Johansson H, Petursdottir V, Nordborg E. The epidemiology of biopsy-positive giant cell arteritis: special reference to changes in the age of the population. Rheumatology (Oxford). 2003;42(4):549-52. 
8. Salvarani C, Crowson CS, O'Fallon WM, Hunder GG, Gabriel SE. Reappraisal of the epidemiology of giant cell arteritis in Olmsted County, Minnesota, over a fifty-year period. Arthritis Rheum. 2004;51(2):264-8.

9. Kobayashi S, Yano T, Matsumoto Y, Numano F, Nakajima N, Yasuda K, et al. Clinical and epidemiologic analysis of giant cell (temporal) arteritis from a nationwide survey in 1998 in Japan: the first government-supported nationwide survey. Arthritis Rheum. 2003;49(4):594-8.

10. Yanagawa H, Nakamura Y, Yashiro M, Oki I, Hirata S, Zhang T, et al. Incidence survey of Kawasaki disease in 1997 and 1998 in Japan. Pediatrics. 2001;107(3):E33.

11. Jiao F, Yang L, Li Y, Qiao J, Guo X, Zhang T, et al. Epidemiologic and clinical characteristics of Kawasaki disease in Shaanxi Province, China, 1993-1997. J Trop Pediatr. 2001;47(1):54-6.

12. Du ZD, Zhang T, Liang L, Meng X, Li T, Kawasaki T, et al. Epidemiologic picture of Kawasaki disease in Beijing from 1995 through 1999. Pediatr Infect Dis J. 2002;21(2):103-7.

13. Mahr A, Guillevin L, Poissonnet M, Aymé S. Prevalences of polyarteritis nodosa, microscopic polyangiitis, Wegener's granulomatosis, and Churg-Strauss syndrome in a French urban multiethnic population in 2000: a capture-recapture estimate. Arthritis Rheum. 2004;51(1):92-9.

14. Ormerod AS, Cook MC. Epidemiology of primary systemic vasculitis in the Australian Capital Territory and south-eastern New South Wales. Intern Med J. 2008;38(11):816-23.

15. Mohammad AJ, Jacobsson LT, Westman KW, Sturfelt G, Segelmark M. Incidence and survival rates in Wegener's granulomatosis, microscopic polyangiitis, Churg-Strauss syndrome and polyarteritis nodosa. Rheumatology (Oxford). 2009;48(12):1560-5.

16. Haugeberg G, Bie R, Bendvold A, Larsen AS, Johnsen V. Primary vasculitis in a Norwegian community hospital: a retrospective study. Clin Rheumatol. 1998;17(5):364-8.

17. Abstracts of the 70th Annual Meeting of the American College of Rheumatology and the 41st Annual Meeting of the Association of Rheumatology Health Professionals, November 10-15, 2006, Washington, DC, USA. Arthritis Rheum. 2006;54(9 Suppl):S36-836.

18. Andrews M, Edmunds M, Campbell A, Walls J, Feehally J. Systemic vasculitis in the 1980s--is there an increasing incidence of Wegener's granulomatosis and microscopic polyarteritis? J R Coll Physicians Lond. 1990;24(4):284-8.

19. Watts RA, Lane SE, Bentham G, Scott DG. Epidemiology of systemic vasculitis: a ten-year study in the United Kingdom. Arthritis Rheum. 2000;43(2):414-9.

20. Patarroyo PA, Restrepo JF, Rojas SA, Rondón F, Matteson EL, Iglesias-Gamarra A. Are classification criteria for vasculitis useful in clinical practice? Observations and lessons from Colombia. J Autoimmune Dis. 2009;6:1.

21. Kallenberg CG, Heeringa P, Stegeman CA. Mechanisms of Disease: pathogenesis and treatment of ANCA-associated vasculitides. Nat Clin Pract Rheumatol. 2006;2(12):661-70.

22. Ferrario F, Vanzati A, Pagni F. Pathology of ANCA-associated vasculitis. Clin Exp Nephrol. 2012.

23. Hedger N, Stevens J, Drey N, Walker S, Roderick P. Incidence and outcome of pauci-immune rapidly progressive glomerulonephritis in Wessex, UK: a 10-year retrospective study. Nephrol Dial Transplant. 2000;15(10):1593-9.

24. Day CJ, Howie AJ, Nightingale P, Shabir S, Adu D, Savage CO, et al. Prediction of ESRD in pauciimmune necrotizing glomerulonephritis: quantitative histomorphometric assessment and serum creatinine. Am J Kidney Dis. 2010;55(2):2508.

25. Hauer HA, Bajema IM, van Houwelingen HC, Ferrario F, Noël LH, Waldherr R, et al. Renal histology in ANCA-associated vasculitis: differences between diagnostic and serologic subgroups. Kidney Int. 2002;61(1):80-9.

26. Neumann I, Regele H, Kain R, Birck R, Meisl FT. Glomerular immune deposits are associated with increased proteinuria in patients with ANCA-associated crescentic nephritis. Nephrol Dial Transplant. 2003;18(3):524-31.

27. Chen M, Kallenberg CG. ANCA-associated vasculitides--advances in pathogenesis and treatment. Nat Rev Rheumatol. 2010;6(11):653-64. 
28. Kain R, Exner M, Brandes R, Ziebermayr R, Cunningham D, Alderson CA, et al. Molecular mimicry in pauci-immune focal necrotizing glomerulonephritis. Nat Med. 2008;14(10):1088-96.

29. Noh JY, Yasuda S, Sato S, Matsumoto M, Kunii Y, Noguchi Y, et al. Clinical characteristics of myeloperoxidase antineutrophil cytoplasmic antibody-associated vasculitis caused by antithyroid drugs. J Clin Endocrinol Metab. 2009;94(8):2806-11.

30. Chen M, Gao Y, Guo XH, Zhao MH. Propylthiouracil-induced antineutrophil cytoplasmic antibody-associated vasculitis. Nat Rev Nephrol. 2012;8(8):476-83. 